\title{
-
}

\section{RESEARCH AND EDUCATION \\ Effect of titanium and zirconia dental implant abutments on a cultivable polymicrobial saliva community}

\author{
Erica D. de Avila, DDS, $\mathrm{PhD},{ }^{a}$ Carlos Eduardo Vergani, DDS, MSc, $\mathrm{PhD},{ }^{\mathrm{b}}$ \\ Francisco A. Mollo Junior, DDS, MSc, $\mathrm{PhD},{ }^{c}$ Miguel Jafelicci Junior, MSc, $\mathrm{PhD},{ }^{d}$ \\ Wenyuan Shi, PhD, ${ }^{e}$ and Renate Lux, $\mathrm{PhD}^{\mathrm{f}}$
}

The biologic complications of peri-implantitis may present a problem during dental implant therapy. ${ }^{1-3}$ Peri-implantitis is associated with about $17 \%$ of installed implants after 10 to 16 years of follow-up. ${ }^{4}$ In a recent review, Mombelli et $\mathrm{al}^{5}$ revealed that the prevalence of peri-implantitis seems to be $20 \%$ between 5 and 10 years after implantation. Although peri-implant disease is immunologically stimulated by the host, the inflammatory process is bacteria dependent. A similar pattern of colonization is present in periodontal and periimplant disease, ${ }^{6-10}$ although with some differences in patients with partial and complete edentulism. ${ }^{11}$ This disease pattern has direct clinical implications, especially with regard to choosing implant surface materials.

Surface attachment is the first step to biofilm development and is an important precursor to the adaptive biofilm formation periods. 2017;118:481-487)

\begin{abstract}
Statement of problem. Peri-implantitis is considered the most important biological complication responsible for late implant failure. The physical chemical properties intrinsic to each material can affect the first step to biofilm development and is an important precursor to the adaptive behavior of pathogenic bacteria species.
\end{abstract}

Purpose. The purpose of this in vitro study was to evaluate the effect of 2 commercially available implant abutment materials on the adhesion phase and biofilm formation.

Material and methods. Disks ( $8 \mathrm{~mm}$ in diameter, $2 \mathrm{~mm}$ thick) of machined pure titanium (Ti) and yttrium-stabilized zirconia $\left(\mathrm{ZrO}_{2}\right)$ materials were used to mimic implant abutments. The physical chemical surface properties were investigated using different approaches. Initial adherent bacteria and biofilm formation were evaluated after 16 and 48 hours by incubating the disks in a rich medium containing representative saliva-derived oral microbial community. Unpaired $t$ test, 2 tailed, was used to compare the groups.

Results. Ti presented lower hydrophobicity and surface free energy values than the $\mathrm{ZrO}_{2}$, and 6.1-fold fewer bacteria adhered to the Ti. After 48 hours, detailed quantitative analysis showed that biofilm biomass and biofilm density were lower on the $\mathrm{Ti}$ disks than on $\mathrm{ZrO}_{2}$. The quantity of phylotypes on the $\mathrm{Ti}$ and $\mathrm{ZrO}_{2}$ surfaces was relatively similar during the attachment and early

Conclusions. Although no difference in the bacteria profile was observed between both materials independent of the time point, the highest level of colonization was on $\mathrm{ZrO}_{2}$. (J Prosthet Dent

behavior of bacteria species as it is the base for the colonization and invasion of pathogens. ${ }^{12}$ The hydrophobic attractive forces and electrostatic charge interactions between cells and material surfaces ${ }^{13-16}$ are

Supported by the São Paulo Research Foundation (FAPESP; grant 2011/05106-6), Coordination for the Improvement of Higher Level Education Personnel (CAPES; grant 5603/13-7), and the Lemann Foundation. Conexão Sistema de Prótese donated the pure commercially available titanium and zirconia stabilized with yttrium disks used in this study.

aPostdoctoral Research Fellow, Department of Dental Materials and Prosthodontics, School of Dentistry at Araraquara, São Paulo State University (UNESP), Araraquara, Brazil; and Research Fellow, School of Dentistry, University of California, Los Angeles, Calif.

bProfessor, Department of Dental Materials and Prosthodontics, School of Dentistry at Araraquara, São Paulo State University (UNESP), Araraquara, Brazil.

'Professor, Department of Dental Materials and Prosthodontics, School of Dentistry at Araraquara, São Paulo State University (UNESP), Araraquara, Brazil.

${ }^{\mathrm{d} P r o f e s s o r, ~ D e p a r t m e n t ~ o f ~ P h y s i c a l ~ C h e m i s t r y, ~ I n s t i t u t e ~ o f ~ C h e m i s t r y, ~ S a ̃ o ~ P a u l o ~ S t a t e ~ U n i v e r s i t y ~(U N E S P), ~ A r a r a q u a r a, ~ B r a z i l . ~}$

eProfessor, School of Dentistry, University of California, Los Angeles, Calif.

fProfessor, School of Dentistry, University of California, Los Angeles, Calif. 


\section{Clinical Implications}

Zirconia promoted a significant microbial saliva community growth compared with titanium. Because esthetic implications are considered an indicator of success and implant abutment surfaces are in intimate contact with the peri-implant tissue, the findings of this study could offer a starting point for clinical studies with patients who are periodontally compromised.

considered the key properties of dental implant surfaces for biofilm formation. The chemical composition and surface characteristics of the different substrates ${ }^{17-25}$ used for abutment components may directly affect microorganism adhesion and oral biofilm maturity. ${ }^{20-28}$

The abutment components seem to be of decisive importance for biofilm formation because of their supragingival and subgingival location. Thus, materials used to manufacture implant abutments should inhibit bacteria colonization on their surface. However, the authors are unaware of any antimicrobial coating of implant abutment surfaces, and therefore, uncoated titanium (Ti) and zirconia $\left(\mathrm{ZrO}_{2}\right)$ are the most common commercially available dental implant abutment materials.

While several investigations have demonstrated differences in terms of biofilm formation on Ti and $\mathrm{ZrO}_{2}$ materials, ${ }^{28-33}$ others have reported no differences in biofilm formation between the material surfaces. ${ }^{34,35}$ Therefore, the effect on the adhesion phase and biofilm formation using human polymicrobial oral communities of 2 different materials was evaluated. The hypothesis was that different material surfaces interfere with the quality and quantity of adhered bacteria, the biofilm formed, and the bacteria profile.

\section{MATERIAL AND METHODS}

Machined pure titanium (grade 2) and yttrium-stabilized zirconia disks (8 $\mathrm{mm}$ in diameter, $2 \mathrm{~mm}$ thick) (Conexão Sistemas de Próteses Ltda) were used in this study. The surface roughness of all disks was determined with a portable roughness analyzer (Surftest SJ-401; Mitutoyo Corp). ${ }^{19,20}$ For each material, each side was measured twice, the mean values were calculated, and the morphology of the disks was examined with a scanning electron microscope (SEM) (JSM-JEOL 7500F; JEOL Ltd). The specimens were directly mounted on aluminum stubs, and the SEM images were obtained in high resolution with the microscope working between 2 and 15 $\mathrm{kV}$. Three disks of each material and 5 areas were analyzed. The surface free energy (SFE) was determined by the contact angle formed between different wet agents and materials to analyze the physicochemical characteristics of Ti and $\mathrm{ZrO}_{2}$ surfaces. The contact angles for liquid drops (aqueous phase with varying $\mathrm{pH}$, water, ethylene glycol, polyethylene glycol, and diiodomethane) were measured by using the sessile drop technique, as described previously. ${ }^{19,20}$ Five disks of each material were used, and the procedure was repeated 3 times to assess the reproducibility of the experiment. The average of each surface and each wetting agent was entered into specialized drop-shaped analysis software (SCASoftware/OCA-20; DataPhysics Instruments $\mathrm{GmbH}$ ), and the SFE was calculated from the concept of polar and dispersion components as described by Owens and Wendt. ${ }^{36}$ Before measurement, each disk was cleaned with acetone to remove any organic material, followed by a 15-minute rinse with ultrapure water in ultrasonic baths. In sequence, the disks were sterilized with gamma irradiation at a dose of $25 \mathrm{kGy}$ from an artificial cobalt 60 source (ISO-11137-1:2006, Sterilization of health care products-radiation-part 1: requirements for development, validation and routine control of a sterilization process for medical devices; this standard was last reviewed and confirmed in 2016).

To simulate clinical conditions and increase the relevance of this in vitro study, a cultivable microbial saliva community representative of the complex oral microbiome was used as an in vitro model biofilm. ${ }^{37,38}$ The bacterial community was grown overnight anaerobically $\left(85 \% \mathrm{~N}_{2}, 10 \% \mathrm{H}_{2} \text {, and } 5 \% \mathrm{CO}_{2}\right)^{38,39}$ at $37^{\circ} \mathrm{C}$ in a modified rich medium (SHI-FSMS) developed to support the high number of oral bacteria from human saliva samples (50\% SHI medium, 25\% filtered saliva [filter pore size $0.22 \mu \mathrm{m}], 0.5 \%$ mannose, $0.5 \%$ sucrose). ${ }^{39}$ Initially the optical density at $600 \mathrm{~nm}$ was adjusted to 0.1 in fresh medium to decrease bacterial concentration, and then $800 \mu \mathrm{L}$ of the oral microbial community was placed onto disks in a sterilized 24-well polystyrene culture plate (Corning Costar cell culture plates; Fisher Scientific). As positive control, the oral microbial suspension was cultured directly on the polystyrene surface of the plate. Additionally, sterile medium was incubated with and without $\mathrm{Ti}$ and $\mathrm{ZrO}_{2}$ disks to act as a negative control. The adhesion phase and biofilm formation were evaluated after 16 and 48 hours' incubation, respectively. After each time point, the disks were transferred to a new 12 well polystyrene culture plate and rinsed 3 times with 1 $\mathrm{mL}$ sterilized phosphate-buffered saline (PBS) before further processing.

The surface property described above was examined as to whether it had any influence on the ability of a complex oral community to adhere and develop biofilms on 2 abutment surfaces. The quantity and quality of bacteria adhered to Ti and $\mathrm{ZrO}_{2}$ materials were evaluated after 16 and 48 hours' incubation using different approaches. The disks were placed in a 24 -well plate with $1 \mathrm{~mL}$ of SHI medium, and the surface was scraped with a 
pipette tip to detach the biofilm. One milliliter of culture was transferred to a 1.5 sterilized Eppendorf tube (tube 1). Subsequently, tube 1 was vortexed, and $100 \mu \mathrm{L}$ from tube 1 was transferred to a new tube containing $900 \mu \mathrm{L}$ of SHI medium (tube 2). The serial dilution procedure was repeated until tube 8 . Twenty-five microliters of each tube was spread on fresh SHI medium agar and the plates kept at $37^{\circ} \mathrm{C}$ under anaerobic conditions. The colonies were counted after 3 days. The overall methodology applied in this experiment followed the detailed sequence as previously described. ${ }^{39}$

To determine the biomass accumulation on $\mathrm{Ti}$ and $\mathrm{ZrO}_{2}$ disk surfaces, the PBS-washed disks were transferred to a new 24-well plate and incubated with $800 \mu \mathrm{L}$ of $0.5 \%$ crystal violet solution for 20 minutes. A similar procedure was conducted for control wells (no disks). After that, the disks were rinsed with PBS to remove excess crystal violet and incubated with $800 \mu \mathrm{L}$ of $95 \%$ ethanol for 15 minutes. The ethanol solution was transferred into cuvettes (polystyrene spectrophotometer cuvette; USA Scientific), and the optical density of the specimens was determined for total biomass assessment at $595 \mathrm{~nm}$. Each data point represented 3 well experiments, and 3 independently repeated tests were performed to ensure reproducibility. To evaluate the viability and density of the complex oral bacteria on both surfaces, the disks were stained with a bacterial viability kit (LIVE/ DEAD BacLight; Invitrogen) according to the manufacturer's instructions. The bacteria adhered, and the biofilm formed was observed through $\times 10$ dry and $\times 40$ oil immersion objectives from a confocal laser scanning microscopy module (LSM 510 v4.2; Carl Zeiss MicroImaging Co Ltd) using an excitation wavelength of 488 $\mathrm{nm}$ and a fluorescence emission range above $505 \mathrm{~nm}$.

Next, confocal microscopy was used to optically slice comparably thick specimens. The biofilm images were obtained from 3 arbitrary positions and vertical and horizontal optical sections with a set slice thickness at 1 $\mu \mathrm{m}$ generated $Z$ series. Confocal images from each disk were exported to a freeware program (Image 1.48 for Macintosh v10.2; http://imagej.nih.gov/ij/download. html) and converted into red, green, and blue. The area occupied and the density of biomass by live bacteria within each section was calculated by using the integrated density of pixels. The analyses were performed in duplicate with 2 repetitions.

Last, to evaluate the effect of both materials on the bacteria profile, each surface was scraped with a sterile pipette tip in a well containing $150 \mu \mathrm{L}$ of PBS, and the total genomic DNA solution was transferred to a $1.5 \mathrm{~mL}$ Eppendorf tube for DNA extraction (MasterPure DNA Purification Kit; Epicentre). The DNA amplification was performed as described by de Avila et al. ${ }^{39}$ Denaturing gradient gel electrophoresis (DGGE) of the polymerase chain reaction (PCR) products was performed using the
DCode System (Bio-Rad Laboratories Inc) at $60 \mathrm{~V}$ and $58^{\circ} \mathrm{C}$ for 17 hours, according to the detailed experimental steps previously published. ${ }^{39}$ A $45 \mu \mathrm{L}$ aliquot of the PCR product was loaded into each well, and electrophoresis through $8 \%$ polyacrylamide gels was completed to separate, identify, and purify nucleic acids.

In sequence, gel images were acquired with the Molecular Imager Gel Documentation system (Bio-Rad Laboratories Inc). Two samples of each material were used for this experiment, and the method was repeated 3 times for each time point. An overnight oral saliva community culture (S) was used as a positive control. The intense DGGE bands were excised, and $5 \mu \mathrm{L}$ of the DNA sample was used as a template for reamplification. Briefly, reamplification was performed with the same universal primers used for PCR amplification, and the product was sent for sequencing using the universal primer. ${ }^{37}$ The 16S DNA sequences were compared with the GenBank sequences by using the BLAST program in the Human Oral Microbiome Database (HOMD) to identify the phenotypic from the oral bacteria.

The results were evaluated as means $\pm \mathrm{SD}$, except for qualitative analysis using confocal microscopy. All statistical analyses were performed by statistical software (Prism v5.0c; GraphPad Software Inc). The unpaired 2-tailed $t$ test was used to compare the Ti and $\mathrm{ZrO}_{2}$ disks $(\alpha=.05)$.

\section{RESULTS}

For Ti disks used in this study, the mean roughness average (Ra) was $0.21 \pm 0.06 \mu \mathrm{m}$ and for $\mathrm{ZrO}_{2}$ was 0.22 $\pm 0.03 \mu \mathrm{m}$. To complement the roughness analysis, the morphology of $\mathrm{Ti}$ and $\mathrm{ZrO}_{2}$ materials was examined at high $(\times 1000)$ magnification. SEM revealed a rough homogeneous surface for $\mathrm{Ti}$ and a smooth surface for $\mathrm{ZrO}_{2}$. Ti surfaces showed a circular configuration of the irregular plane, smooth, and rough surface areas (Fig. 1A), whereas for $\mathrm{ZrO}_{2}$, a spherically shaped characteristic was detected in granules (Fig. 1B).

According to Table 1, although both materials were hydrophobic with contact angles higher than 50 degrees, a significant difference was noted between them, with $\mathrm{ZrO}_{2}$ presenting less wetting with water. Conversely, no significant difference was noted between the contact angle of diiodomethane and materials, revealing a similar nonpolar characteristic of $\mathrm{Ti}$ and $\mathrm{ZrO}_{2}$. The variability of the data collected for the contact angle of each liquid to each material was evaluated by descriptive analysis. Low $\mathrm{SD}$ values were assumed, and the final averages were inserted into the software (SCA-Software/OCA-20) to obtain the SFE values. $\mathrm{ZrO}_{2}$ specimens presented higher surface tension $\left(6.1 \mathrm{~mJ} / \mathrm{m}^{2}\right)$ than $\mathrm{Ti}\left(5.75 \mathrm{~mJ} / \mathrm{m}^{2}\right)$.

Colony-forming unit per milliliter disclosed a statistically significant difference $(P=.019)$ in the overall bacteria adhered, with 6.1-fold more colonies evident on the 

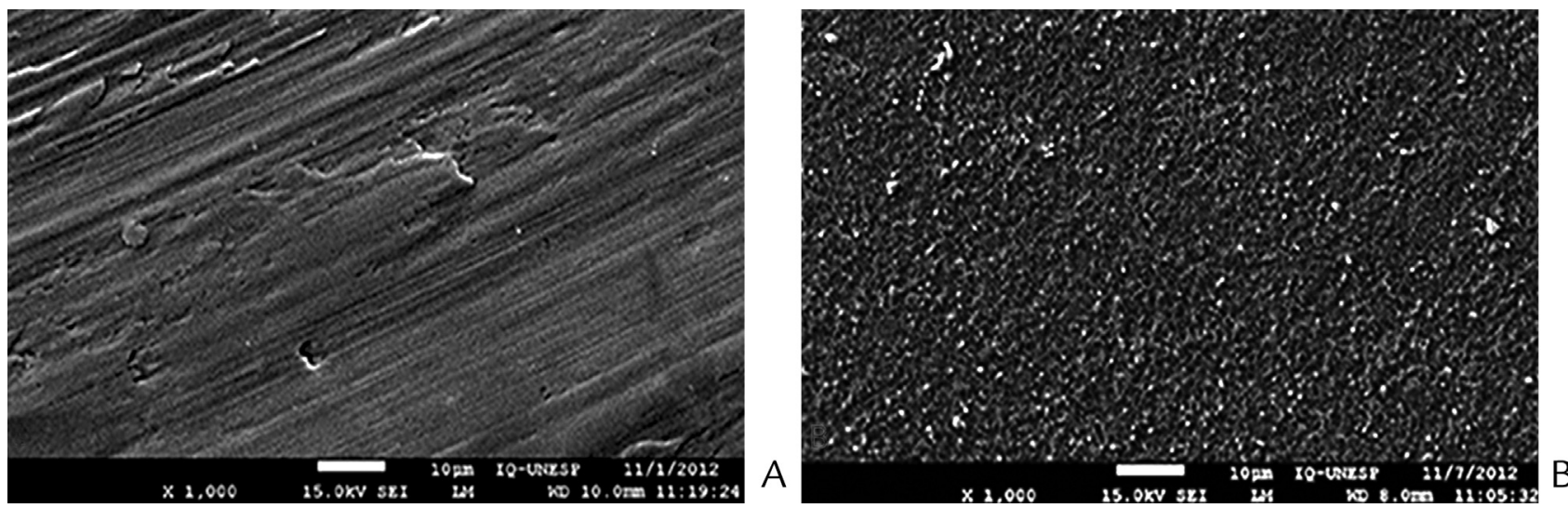

Figure 1. Scanning electron microscope images showing surface topography. A, Ti disk. $\mathrm{B}, \mathrm{ZrO}_{2}$ disk. (Original magnification, $\times 1000$.)

Table 1. Means $\pm S D$ of contact angle $(\theta)$ of liquid for each specimen

\begin{tabular}{lcc}
\hline & \multicolumn{2}{c}{ Specimen } \\
\cline { 2 - 3 } Wetting Agent & $\mathbf{T i}$ & $\mathbf{Z r O}_{\mathbf{2}}$ \\
\hline Water & $67.73 \pm 3.32$ & $73.14 \pm 1.82$ \\
\hline Ethylene & $43.83 \pm 1.27$ & $39.45 \pm 3.80$ \\
\hline Polyethylene & $25.90 \pm 3.46$ & $23.39 \pm 1.06$ \\
\hline Diiodomethane & $24.09 \pm 1.82$ & $24.77 \pm 1.56$ \\
\hline
\end{tabular}

$\mathrm{ZrO}_{2}$ than Ti surfaces. Because the attached phase showed fewer salivary bacteria adhered to Ti disks, this outcome was evaluated to see whether it would persist during the biofilm formation and growth process. Colony-forming unit per milliliter also disclosed a statistically significant difference $(P=.046)$ in overall biofilm formed after 48 hours with 1.6-fold more bacteria adhered on $\mathrm{ZrO}_{2}$ than on Ti surfaces (Fig. 2).

The confocal microscopy images of the surface attached biomass confirmed that Ti disks accumulated significantly fewer bacteria compared with their counterparts (Fig. 3A, B). Further, the biofilm viability of both materials was similar, as revealed by fluorescent stain. The difference in biofilm formation between Ti and $\mathrm{ZrO}_{2}$ disks was also confirmed by confocal microscopy analysis (Fig. 3C, D). The observation under confocal laser microscopy showed that the biofilm thickness on $\mathrm{ZrO}_{2}$ was deeper than that of the Ti group (Fig. 3E, F). Quantitative measurements from images acquired by confocal analysis revealed that the density of adherent bacteria was 1.6-fold higher on the $\mathrm{ZrO}_{2}$ than on the Ti disks (Fig. 4) after 16 hours and that this difference remained after 48 hours.

Consistent with confocal analysis, crystal violet staining showed substantially higher biomass at both time points, with 2.7-fold more bacteria adhered on $\mathrm{ZrO}_{2}$ than on Ti disks and 2.2-fold more biofilm developed on $\mathrm{ZrO}_{2}$ than on Ti disks (Fig. 5). The next goal was to observe whether the different abutment material surfaces affected the biofilm bacterial community. DGGE analyses demonstrated that the quantity of phylotypes on the Ti and $\mathrm{ZrO}_{2}$ surfaces was relatively similar during the

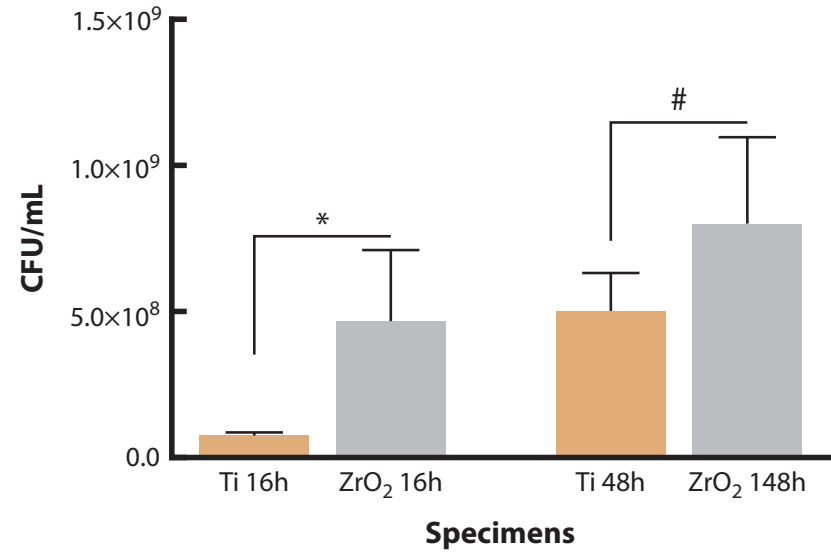

Figure 2. Effect of $\mathrm{Ti}$ and $\mathrm{ZrO}_{2}$ material surfaces on bacterial attachment and biofilm formation evaluated after 16 and 48 hours' incubation using quantitative culture counts (in $\mathrm{CFU}$ ); $\mathrm{CFU} / \mathrm{mL}$ was significantly reduced on Ti disks. Data shown as means $\pm \mathrm{SD}(\mathrm{n}=9)$. ${ }^{*}{ }^{*} P<.05$. CFU, colonyforming units.

attachment and early biofilm formation periods (Fig. 6). However, some differences on weakly and strongly adherent biofilm bacteria were observed for both time points. The intensity of bands 2 and 3 were highest during the adhesion phase (16 hours of incubation). The similarity of bacteria composition persisted after 48 hours, but the time affected the dominance of some bacteria species. Bands 1, 5, and 6, identified as Fusobacterium periodonticum, Neisseria subflava, and Alloprevotella sp, respectively, became more intense on $\mathrm{Ti}$ and $\mathrm{ZrO}_{2}$ after 48 hours, indicating that biofilm formation on those materials is time dependent.

\section{DISCUSSION}

Studies have shown that individuals treated for periodontitis may experience more implant failure, so a better understanding of the interface between prosthetic superstructure and implants is necessary. The authors are unaware of previous studies analyzing a cultivable 

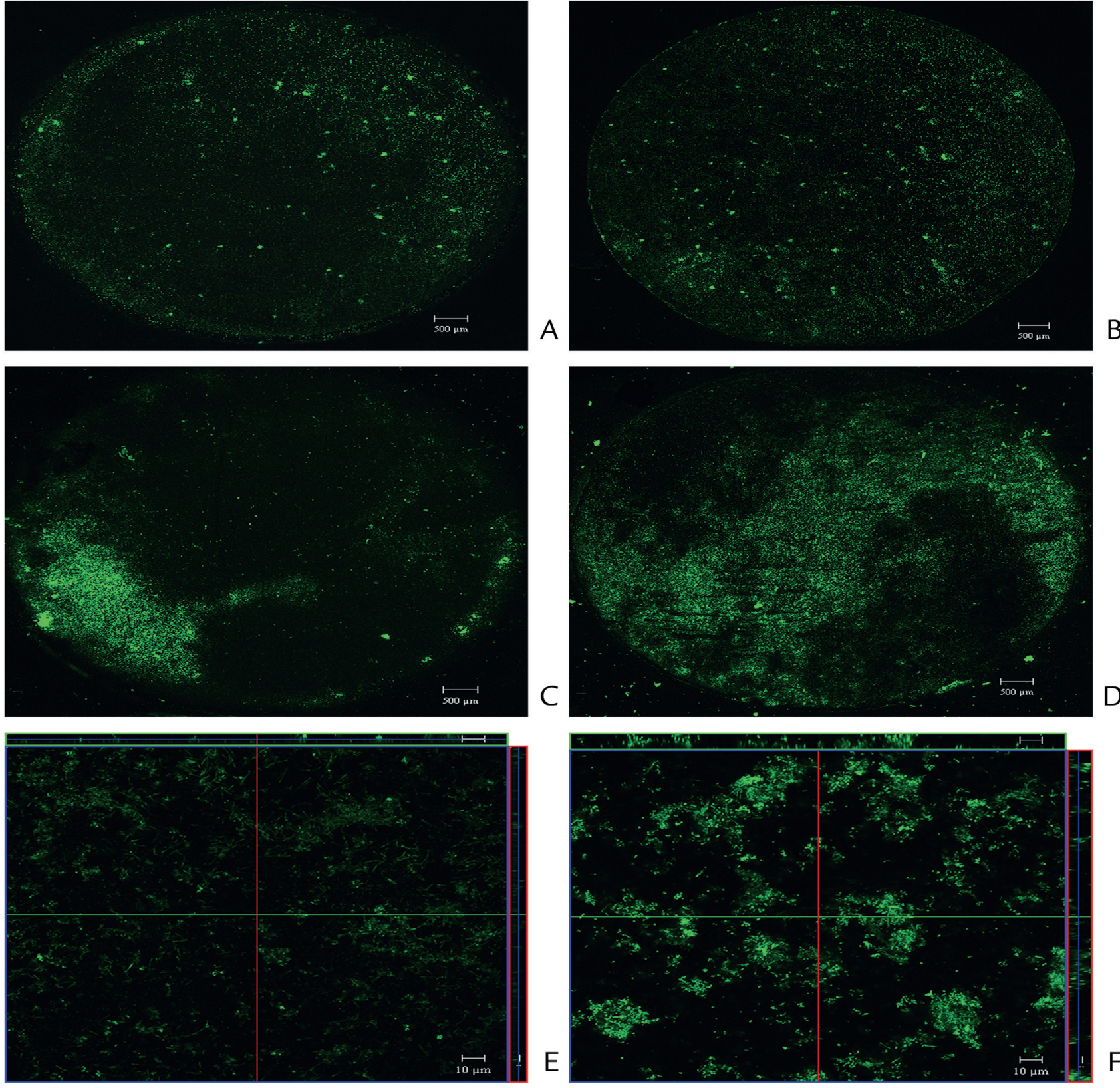

Figure 3. Effect of $\mathrm{Ti}$ and $\mathrm{ZrO}_{2}$ material surfaces on bacterial attachment and biofilm formation evaluated after 16 and 48 hours' incubation using confocal microscopy. (Original magnification, $\times 10$.) A, Ti disks after 16 hours' incubation. $\mathrm{B}, \mathrm{ZrO}_{2}$ disks after 16 hours' incubation. $\mathrm{C}$, Ti disks surfaces after 48 hours' incubation. $\mathrm{D}, \mathrm{ZrO}_{2}$ disks after 48 hours' incubation. E, Images in $Z$ stacks revealed biofilm thickness formed on Ti disk surfaces. $\mathrm{F}$, Images in $Z$ stacks revealed biofilm thickness formed $\mathrm{ZrO}_{2}$ disk surfaces.

polymicrobial community representative of the oral cavity $^{38}$ on 2 commercial types of implant abutments. The data led to acceptance of one of the hypotheses: that more biofilm accumulated on $\mathrm{ZrO}_{2}$ than on Ti materials. However, the other hypothesis was rejected because the type of material did not affect the bacterial profile.

The surface properties of materials have a marked influence on the early phases of biofilm development in that smooth surfaces and those with the low SFE feature may have less bacterial adherence than rough substrates. ${ }^{21,23}$ For the purpose of this study, a standard roughness was chosen for the experimental Ti and $\mathrm{ZrO}_{2}$ abutments that approached the optimal roughness as previously described ${ }^{10,18}$ for permucosal implant abutments. The goal in this study was to eliminate the roughness variable, keep the homogeneity of groups, and focus on the effect of abutment materials on bacterial attachment and biofilm formation.

Differences in bacterial colonization and biofilm formation probably resulted from differences in the chemical 


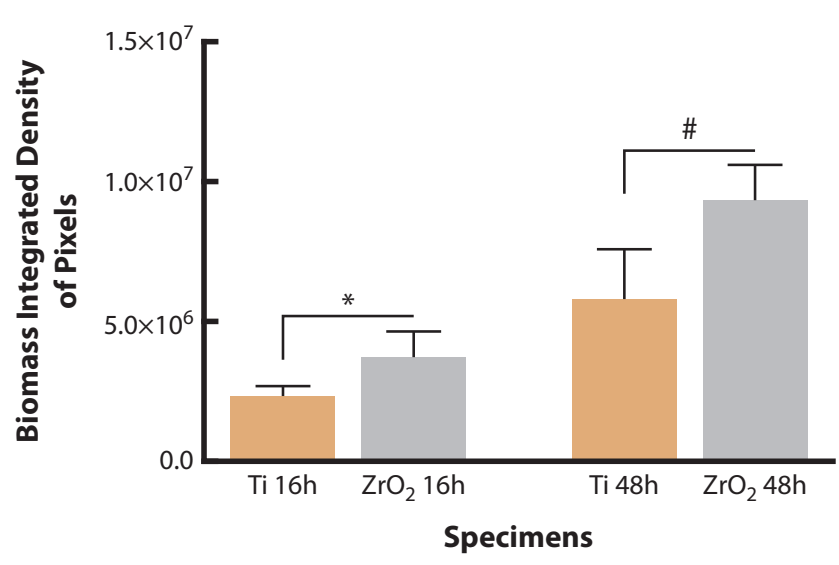

Figure 4. Integrated density significantly reduced on Ti disks (brown bar, Ti). Data shown as means \pm SD. ${ }^{*}{ }^{*} P<.05$ indicates statistically significant difference between $\mathrm{Ti}$ and $\mathrm{ZrO}_{2}$ disks.

composition and consequently differences in SFE (electrical conductivity). On the basis of the analysis of the total number of bacteria adhered in the initial culture stage and in a mature biofilm to different surfaces, more bacterial accumulation was observed on the $\mathrm{ZrO}_{2}$ surfaces, the most hydrophobic material with the highest value of surface tension. The positive correlation between SFE and bacterial adhesion depended on the similar chemical nature of both surfaces and the prokaryotic cells. ${ }^{13,16}$

Fewer bacteria (6.1-fold) adhered to Ti than to $\mathrm{ZrO}_{2}$. This reduction was also reflected by reduced biomass and biofilm density. The reduction in biofilm formation was sustained most notably after 48 hours. These data are in contrast with most studies that reported no difference between biofilm formations on these materials, or fewer bacteria adhered to $\mathrm{ZrO}_{2}$ than the Ti substrate. ${ }^{33,35}$ However, the chemical and physical properties of surfaces (surface wettability of materials) combined with one or a few species of bacteria do not reflect the actual effect of the material in the oral cavity. ${ }^{25,35}$ A previous investigation $^{22}$ also found no difference in biofilm formation between $\mathrm{Ti}$ and $\mathrm{ZrO}_{2}$ substrates for implant abutment fabrication. However, the authors kept the specimens immersed in saliva for 2 hours before the biofilm development, which may have affected the SFE, making it similar between the materials. ${ }^{22}$ Consequently, the interactions between the hydrophobic and hydrophilic regions of the outer cell wall ${ }^{24}$ and the material surface may also have been similar.

An intriguing observation in this study was the number of microorganisms determined in multispecies biofilm exposing the specimens to a suspension of Streptococcus gordonii, Streptococcus mutans, Actinomyces naeslundii, and Candida albicans. ${ }^{22}$ Because bacteria express a wide variety of complex molecules that can contribute to the overall tendencies of microorganisms interacting with other cells, the selected microorganism

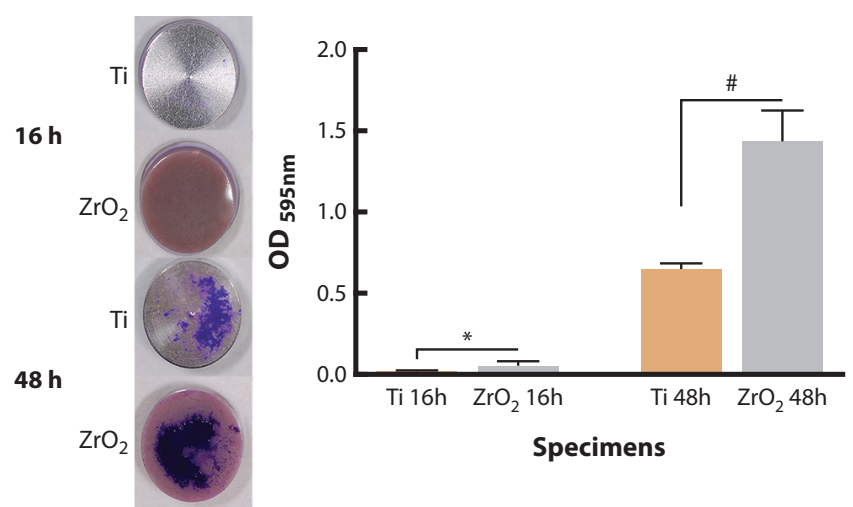

Figure 5. Effect of $\mathrm{Ti}$ and $\mathrm{ZrO}_{2}$ material surfaces on biomass of bacterial attachment and biofilm formed evaluated after 16 and 48 hours' incubation using crystal violet staining. Statistically significantly higher biomass of bacterial attachment on $\mathrm{ZrO}_{2}$ (gray bar, $\mathrm{ZrO}_{2}$ ) than Ti disks (brown bar, Ti). Data are shown as means $\pm \mathrm{SD}(\mathrm{n}=9)$. ${ }^{*}{ }^{*} P<.05$ indicates statistically significant difference between $\mathrm{Ti}$ and $\mathrm{ZrO}_{2}$ disks.

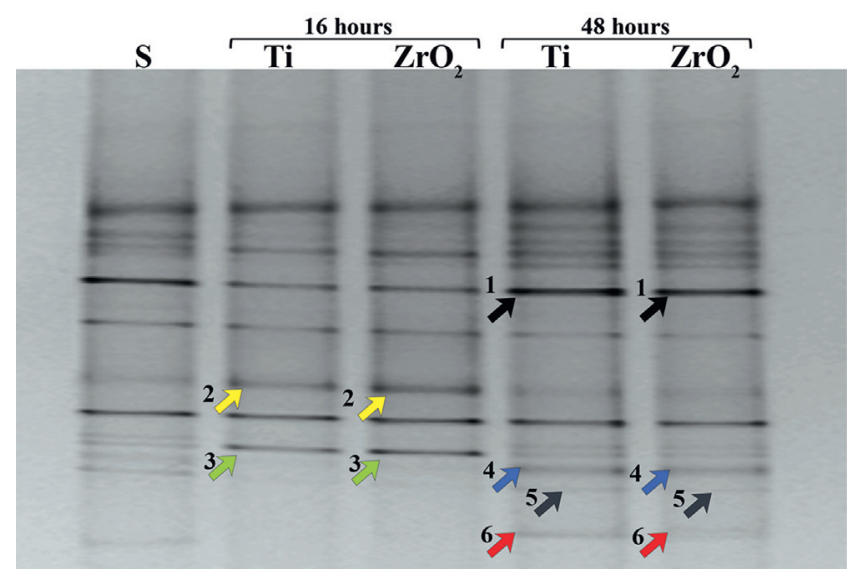

Figure 6. Denaturing gradient gel electrophoresis (DGGE) analysis of oral microbial communities formed on $\mathrm{Ti}$ and $\mathrm{ZrO}_{2}$ disk surfaces after 16 and 48 hours' incubation. Bands indicated by arrows were excised and DNA sequenced. Microbial identities: (1) Fusobacterium periodonticum, (2) Streptococcus sp, (3) Gemella sanguinis, (4) Veillonella parvula,

(5) Neisseria subflava, and (6) Alloprevotella sp.

species can create a final energy and change the interaction to their environment. ${ }^{15}$ Because interaction among microorganisms is fundamental for initial colonization and subsequent biofilm formation on dental surfaces, the limitation of the in vitro biofilm models described in the literature so far may explain the inconsistent results.

Overall, comparable microorganisms are found around newly placed implants and the remaining dentition. This can also include periodontopathogenic species, which might even be considered a risk for future peri-implant infections. Because Ti accumulated fewer bacteria than $\mathrm{ZrO}_{2}$ onto the surface, whether material features would also affect the profile of bacteria colonization was investigated. No differences were observed in bacterial composition in the attachment phase. The effect 
of $\mathrm{Ti}$ and $\mathrm{ZrO}_{2}$ beyond the early stages continued over time. After 48 hours of incubation, the bacterial profile, measured by the intensity of the bands, showed no differences between materials, but the intensity was different compared with the first time point. Ti and $\mathrm{ZrO}_{2}$ are considered highly hydrophobic materials because of their chemical composition; the low polarity of their surfaces will attract molecules with the same chemical composition. These concepts may explain the similarity of the bacterial profile at both time points.

\section{CONCLUSIONS}

On the basis of the results of this in vitro study, the following conclusion was drawn:

The initial attachment phase and biofilm formation are affected by substrate type, with $\mathrm{ZrO}_{2}$ accumulating significantly more bacteria and biofilm on the material surfaces than Ti.

\section{REFERENCES}

1. Isidor F. Loss of osseointegration caused by occlusal load of oral implants. A clinical and radiographic study in monkeys. Clin Oral Implants Res 1996:7:143-52.

2. Esposito M, Thomsen P, Ericson LE, Lekholm U. Histopathologic observations on early oral implant failures. Int J Oral Maxillofac Implants 1999;14:798-810.

3. Piattelli A, Vrespa G, Petrone G, Iezzi G, Annibali S, Scarano A. Role of the microgap between implant and abutment: a retrospective histologic evaluation in monkeys. J Periodontol 2003;74:346-52.

4. Simonis P, Dufour T, Tenenbaum H. Long-term implant survival and success: a 10-16-year follow-up of non-submerged dental implants. Clin Oral Implants Res 2010;21:772-7.

5. Mombelli A, Muller N, Cionca N. The epidemiology of peri-implantitis. Clin Oral Implants Res 2012;23(suppl 6):67-76.

6. Mombelli A, Decaillet F. The characteristics of biofilms in peri-implant disease. J Clin Periodontol 2011;38:203-13.

7. Aouirre-Zorzano LA, Estefania-Fresco R, Telletxea O, Bravo M. Prevalence of peri-implant inflammatory disease in patients with a history of periodontal disease who receive supportive periodontal therapy. Clin Oral Implants Res 2015;26:1338-44.

8. Quirynen M, Teughels W. Microbiologically compromised patients and impact on oral implants. Periodontol 2000 2003;33:119-28.

9. Mombelli A. In vitro models of biological responses to implant microbiological models. Adv Dent Res 1999;13:67-72.

10. Quirynen M, Vogels R, Peeters W, van Steenberghe D, Naert I, Haffajee A Dynamics of initial subgingival colonization of "pristine" peri-implant pockets. Clin Oral Implants Res 2006;17:25-37.

11. Apse P, Ellen RP, Overall CM, Zarb GA. Microbiota and crevicular fluid collagenase activity in the osseointegrated dental implant sulcus: a comparison of sites in edentulous and partially edentulous patients. J Periodontal Res 1989:24:96-105.

12. Foster JS, Kolenbrander PE. Development of a multispecies oral bacterial community in a saliva-conditioned flow cell. Appl Environ Microbiol 2004;70: 4340-8.

13. Ellepola AN, Chandy R, Khan ZU, Samaranayake LP. Caspofungin-induced in-vitro post-antifungal effect and its impact on adhesion related traits of oral Candida dubliniensis and Candida albicans isolates. Microbiol Immunol 2016;60:160-7.

14. Ener B, Douglas LJ. Correlation between cell-surface hydrophobicity of Candida albicans and adhesion to buccal epithelial cells. FEMS Microbiol Lett 1992;78:37-42.

15. Popovici J, White CP, Hoelle J, Kinkle BK, Lytle DA. Characterization of the cell surface properties of drinking water pathogens by microbial adhesion to hydrocarbon and electrophoretic mobility measurements. Colloids Surf B Biointerfaces 2014;118:126-32

16. Masuoka J, Hazen KC. Cell wall mannan and cell surface hydrophobicity in Candida albicans serotype A and B strains. Infect Immun 2004;72: 6230-6.

17. Almaguer-Flores A, Olivares-Navarrete R, Wieland M, Ximenez-Fyvie LA, Schwartz Z, Boyan BD. Influence of topography and hydrophilicity on initia oral biofilm formation on microstructured titanium surfaces in vitro. Clin Oral Implants Res 2012;23:301-7.
18. Bollen CM, Lambrechts P, Quirynen M. Comparison of surface roughness of oral hard materials to the threshold surface roughness for bacterial plaque retention: a review of the literature. Dent Mater 1997;13:258-69.

19. de Avila ED, Avila-Campos MJ, Vergani CE, Spolidorio DM, Mollo Fde A Jr. Structural and quantitative analysis of a mature anaerobic biofilm on different implant abutment surfaces. J Prosthet Dent 2016;115:428-36.

20. de Avila ED, de Molon RS, Lima BP, Lux R, Shi W, Junior MJ, et al. Impact of physical chemical characteristics of abutment implant surfaces on bacteria adhesion. J Oral Implantol 2016;42:153-8.

21. Elter C, Heuer W, Demling A, Hannig M, Heidenblut T, Bach FW, et al. Supraand subgingival biofilm formation on implant abutments with different surface characteristics. Int I Oral Maxillofac Implants 2008:23:327-34.

22. Hahnel S, Wieser A, Lang R, Rosentritt M. Biofilm formation on the surface of modern implant abutment materials. Clin Oral Implants Res 2015;26: 1297-301.

23. Quirynen M, van der Mei HC, Bollen CM, Schotte A, Marechal M, Doornbusch GI, et al. An in vivo study of the influence of the surface roughness of implants on the microbiology of supra- and subgingival plaque. J Dent Res 1993:72:1304-9.

24. Renner LD, Weibel DB. Physicochemical regulation of biofilm formation. MRS Bull 2011;36:347-55.

25. Zhao B, van der Mei HC, Subbiahdoss G, de Vries I, Rustema-Abbing M, Kuijer R, et al. Soft tissue integration versus early biofilm formation on different dental implant materials. Dent Mater 2014;30:716-27.

26. de Avila ED, de Molon RS, Vergani CE, Mollo FA Jr, Salih V. The relationship between biofilm and physical-chemical properties of implant abutment materials for successful dental implants. Materials 2014;7:3651-62.

27. de Avila ED, de Molon RS, Spolidorio DMP, Mollo FA Jr. Implications of surface and bulk properties of abutment implants and their degradation in the health of periodontal tissue. Materials 2013;6:5951-66.

28. Busscher HJ, Rinastiti M, Siswomihardjo W, van der Mei HC. Biofilm formation on dental restorative and implant materials. J Dent Res 2010;89: 657-65.

29. Auschill TM, Arweiler NB, Brecx M, Reich E, Sculean A, Netuschil L. The effect of dental restorative materials on dental biofilm. Eur J Oral Sci 2002;110:48-53.

30. de Oliveira GR, Pozzer L, Cavalieri-Pereira L, de Moraes PH, Olate S, de Albergaria Barbosa JR. Bacterial adhesion and colonization differences between zirconia and titanium implant abutments: an in vivo human study. J Periodontal Implant Sci 2012;42:217-23.

31. Yamane K, Ayukawa Y, Takeshita T, Furuhashi A, Yamashita Y, Koyano K. Bacterial adhesion affinities of various implant abutment materials. Clin Oral Implants Res 2013;24:1310-5.

32. Sanchez MC, Llama-Palacios A, Fernandez E, Figuero E, Marin MJ, Leon R, et al. An in vitro biofilm model associated to dental implants: structural and quantitative analysis of in vitro biofilm formation on different dental implant surfaces. Dent Mater 2014;30:1161-71.

33. Nascimento C, Pita MS, Fernandes FH, Pedrazzi V, de Albuquerque Junior RF, Ribeiro RF. Bacterial adhesion on the titanium and zirconia abutment surfaces. Clin Oral Implants Res 2014;25:337-43.

34. do Nascimento C, da Rocha Aguiar C, Pita MS, Pedrazzi V, de Albuquerque RF Ir, Ribeiro RF. Oral biofilm formation on the titanium and zirconia substrates. Microsc Res Tech 2013;76:126-32.

35. van Brakel R, Cune MS, van Winkelhoff AJ, de Putter C, Verhoeven JW, van der Reijden W. Early bacterial colonization and soft tissue health around zirconia and titanium abutments: an in vivo study in man. Clin Oral Implants Res 2011;22:571-7.

36. Owens DK, Wendt RC. Estimation of surface free energy of polymers. J Appl Polym Sci 1969;13:1741-7.

37. Edlund A, Yang Y, Hall AP, Guo L, Lux R, He X, et al. An in vitro biofilm model system maintaining a highly reproducible species and metabolic diversity approaching that of the human oral microbiome. Microbiome 2013;1:25.

38. Tian $Y$, He X, Torralba M, Yooseph S, Nelson KE, Lux R, et al. Using DGGE profiling to develop a novel culture medium suitable for oral microbial communities. Mol Oral Microbiol 2010;25:357-67.

39. de Avila ED, Lima BP, Sekiya T, Torii Y, Ogawa T, Shi W, et al. Effect of UV-photofunctionalization on oral bacterial attachment and biofilm formation to titanium implant material. Biomaterials 2015;67:84-92.

\section{Corresponding author:}

Dr Erica Dorigatti de Avila

Department of Dental Materials and Prosthodontics

School of Dentistry at Araraquara

São Paulo State University (UNESP)

Rua Humaitá, 1680, Araraquara

São Paulo, 14801-903

BRAZIL

Email: erica.fobusp@yahoo.com.br

Copyright $($ C 2017 by the Editorial Council for The Journal of Prosthetic Dentistry. 